\title{
TOWARDS MOBILE INFORMATION SYSTEMS
}

\author{
Juhani Iivari
}

Department of Information Processing Science, University of Oulu, P.O. Box 3000, FIN90014 Oulun yliopisto, Finland

\begin{abstract}
The contention of the present paper is that information systems proper forn a significant application area of mobile technology. For that purpose the paper analyses the concept of mobility in the context of information systems using a sound metamodel for information systems. The anlysis makes it possible to make sense of different examples of mobile information systems and possibly to innovate new ones.
\end{abstract}

Keywords: mobile information system, mobile application, mobile service

\section{INTRODUCTION}

After the boom of mobile computing started in the early 1990's, the word "mobile" is easily used just as a selling argument without much attention to its meaning. It has served as a shorthand to mean that some service or product is accessed using a mobile device, a cellular phone for example. The term "mobile Internet" is an example of this. However, if we wish to have a more scientific understanding of mobility, we should be more careful with the terms.

Many experts claim that this first decade of the $21^{\text {st }}$ century will be the decade of mobile computing (Urbaczewski et al., 2003), even though the expectations tend to be unrealistically high as in the case of every technology boom. In fact, the mobile field still waits for a second "killer application", if short messages are considered the first. It may be that it is not realistic to expect new universal or horizontal killer applications anymore. Instead the applications of mobile computing may be more vertical targeted to 
specific application domains. This paper considers information systems one possible application area of mobile computing.

Accordingly, the present paper focuses on mobility in the context of information systems. It analyses different aspects of spatial mobility in the IS context. To ensure systematic analysis and to integrate the aspects of mobility, the paper applies a sound metamodel for an information system (Iivari, 1989; Iivari 1990) as a structuring framework. The analysis provides a framework for understanding mobility, to innovate new mobile applications, and to develop them.

\section{THE METAMODEL FOR AN INFORMATION SYSTEM}

An information system (IS) is a computer-supported system with the purpose "to supply its groups of users (...) with information about a set of topics to support their activities" (Gustafsson et al., 1982). In addition to conventional information systems the above definition covers all digital content that aims at informing about some topic (such as company web pages).

In consistence with Gustafsson et al. (1992), Iivari $(1989,1990)$ proposes a metamodel for an information system consisting of three major levels of modeling or abstraction for an information system:

1. The organizational level (the users and their activities).

2. The conceptual/infological level (information and the topics).

3. The datalogical/technical level (the technical implementation)

The three levels of modeling are abstractions from three different, even though interdependent domains: the host organization, in wilich the information system is to be "embedded", the universe of discourse, about which the information system is to communicate information, and the technology to be used in the technical implementation of the system.

The organizational level consists of two sublevels: the (re)designed organizational context and the application concept. The (re)designed organizational context describes organizational actors/units, organizational functions ("business processes") affected and/or redesigned by the information system in question. The application concept summarizes the IS services - organizational information types, information processing functions and communication relationships - delegated to the information system.

The metamodel for the conceptual/infological level identifies three sublevels: the Universe of Discourse (UoD), IS specifications and the user interface. The idea of the UoD level is to formalize the model of the "real" world underlying the information system. The level of IS specifications describes the information content and functionality of the system, ignoring the external 
representation of the system to the users. The external representation is the topic to be addressed at the level of user interface. The user interface defines how the content abstractions are made accessible and visible to the user.

Information systems are information specific, they inform about specific topics. An essential part of the systems development is to specify their information content and structure. The above metamodel provides and integrates three perspectives into the analysis and design of the information content of system: the "ontological-conceptual/" perspective, the "information-document perspective" and the "user interface" perspective.

The above metamodel has successfully been applied to identify and categorize objects in the object-orientation analysis (Iivari, 1990) and to analyse object-oriented methods (Iivari, 1994) as well as to structure IS security issues (Siponen, 2001). In the following it will be applied to analyse mobility in the context of information systems.

\section{MOBILITY IN THE CONTEXT OF INFORMATION SYSTEMS}

The metamodel for an information system allows to integrate a number of aspects of mobility into a systematic framework. At the organizational level, and more specifically at the sublevel of (re)designed organizational (or interorganizational) context, one can distinguish business models for mobile services (especially for mobile commerce) and models of mobile work. Business models discussed in Tsalgatidou and Pitoura (2001) and Varshney (2003), for example, describe business actors, their roles and the product, service and information flows between them in providing the services: This paper will choose more a customer focus on the mobile activities/work to be supported by the mobile services. If a customer or a user is not specially interested in the underlying business model of a mobile service, the business model should be as invisible as possible to her.

Mobility of work means that the work may be performed at different places either locally (e.g. within a building) or more remotely. This mobility easily implies that the context of work may change. Gorlenko and Merrick (2003) distinguish mobile office context and mobile fieldwork context in the case mobile work. In the former case they assume that the computer is the primary task for the user and walking and manipulating other objects secondary. In the mobile field context moving and working with other objects other than the computer is primary, and the use of computer only secondary. Referring to Kristoffersen and Ljungberg (1999) they suggest that in the mobile field context visual attention of users is mainly directed to events outside the computer, users hands are commonly engaged with a variety of 
physical objects unrelated with the computer device, and users often must be move all the time. Following again Kristoffersen and Ljungberg (1999) they propose that there are two ways of operating the computer in the mobile field context: the user may "make place" for interacting with the device, that is interrupt the main task in order to interact with the computer device, or "take place", i.e. to interact with the device while executing the main task (e.g. repair work on the field).

The study of Perry et al. (2001) mainly concerns mobile office context. They followed closely business trips of 17 mobile workers who mainly worked in multiple, but stationary locations. They summarize their findings in four points: planning opportunistic access to information (e.g. carrying particular technologies and documents just in case), working in dead time, use of the mobile phone as a device proxy (accessing remote technological and informational resources using a mobile phone), and use of technologies for remote awareness monitoring (of activities of remote colleagues).

Table 1 suggests that changing context is not mobility as such, but a natural consequence of mobility. Spatial mobility implies that the location of the user and the device may change, and consequently the physical environment (e.g. temperature and light), artifacts in the environment (especially ICT artifacts capable to communicate with the focal information system in question), users activities may also change while moving, and participants involved.

The distinction between wandering, traveling and visiting (Dahlbom and Ljungberg, 1998) clearly concerns potential users of the system. Wandering users rather than traveling or visiting ones may be more interesting in the case of mobility, since the latter can easily be supported by portable devices such as laptops. One should note, however, these are not mutually exclusive categories. A traveling or visiting user may be wandering at the same time and even in the same situation (e.g. wandering in a train while traveling). Then a crucial question often is if one device can satisfactorily support wandering, traveling and visiting.

The distinction between on-site movers, yo-yos, pendulums, nomads, carriers (Lilischkis, 2003) can be interpreted as a hybrid one that tells something about the mobile work and about potential users of the systems developed to support the mobile work in question.

Table 1. Dimensions of mobility of mobile information systems

\begin{tabular}{|l|l|}
\hline Level & \multicolumn{1}{|c|}{ Dimension of mobility } \\
\hline \multicolumn{1}{|c|}{ Organizational level } \\
\hline $\begin{array}{l}\text { (Re)designed } \\
\text { organizatio- } \\
\text { nal or inter- } \\
\text { organizatio- }\end{array}$ & $\begin{array}{l}\text { Mobile work/activity } \\
\text { - local mobility, remote mobility (Luff and Heath, 1998) }\end{array}$ \\
\hline
\end{tabular}




\begin{tabular}{|c|c|}
\hline nal context & $\begin{array}{l}\text { vs. mobile field context (Gorlenko and Merrick, 2003; Pascoe et al., 2000) } \\
\text { - on-site movers, yo-yos, pendulums, nomads, carriers (Lilischkis, (2003) } \\
=> \\
\text { Changing context ( } \approx \text { Gorlenko and Merrick, 2003; Krogstie et al., 2003; } \\
\text { Tarasewich, 2003): } \\
\text { - location, environmental context, artifact context, activity context, parti- } \\
\text { cipant context } \\
\text { - activity “mobility", social "mobility" (Lyytinen and Yoo, 2002) }\end{array}$ \\
\hline $\begin{array}{l}\text { Application } \\
\text { concept }\end{array}$ & $\begin{array}{l}\text { Mobile user } \\
\text { - wandering, traveling, visiting (Dahlbom and Ljungberg, 1998) } \\
\text { - on-site movers, yo-yos, pendulums, nomads, carriers (Lilischkis, (2003) } \\
\text { Wireless interaction } \\
\text { - stationary interaction (Perry et al., 2001) - mobile interaction (Gorlenko } \\
\text { and Merrick, 2003; Pascoe et al., 2000) } \\
\text { Context-aware IS services - non-context-aware IS services } \\
\text { - location-aware, environment-aware, artifact-aware, activity-aware, par- } \\
\text { ticipant- aware, user-aware ( } \approx \text { Gorlenko and Merrick, 2003, Krogstie et al., } \\
\text { 2003; Tarasewich, 2003) }\end{array}$ \\
\hline \multicolumn{2}{|c|}{ Conceptual/infological level } \\
\hline $\begin{array}{l}\text { Universe of } \\
\text { Discourse }\end{array}$ & Fixed, portable and mobile entities (Varshney, 2003) \\
\hline $\begin{array}{l}\text { IS specifica- } \\
\text { tions }\end{array}$ & $\begin{array}{l}\text { Location-dependent information about mobile entities } \\
=>\text { Context-aware functionality }\end{array}$ \\
\hline $\begin{array}{l}\text { User inter- } \\
\text { face }\end{array}$ & $\begin{array}{l}\text { Mobile terminal } \\
\text { Micro mobility (Luff and Heath, 1998) } \\
\text { => Context-aware user interface } \\
\text { => Display mobility }\end{array}$ \\
\hline \multicolumn{2}{|c|}{ Datalogical/technical level } \\
\hline $\begin{array}{l}\text { Hardware } \\
\text { and } \\
\text { network }\end{array}$ & $\begin{array}{l}\text { Mobile devices } \\
\text { Wimed --wireless }\end{array}$ \\
\hline Data & Mobile data (data migration) \\
\hline Programs & Mobile programs (program migration) \\
\hline
\end{tabular}

When considering the application concept for a mobile information system, one should decide whether stationary of mobile wireless interaction (Gorlenku and Merrick, 2003) with the system is needed. In the stationary wireless interaction the interaction session is assumed to take place in one place while in mobile interaction both the user and the device may change the location while interacting.

Another aspect of the application concept concerns whether the system is context aware or not. Mobility almost by definition implies that that the location of the user changes. It is not necessary to restrict context-awareness to location only (Schmidt et al., 1999).

When looking at mobility at the conceptual/infological level, the first aspect is that the entities of interest are mobile. The users may also be entities of interest in the system. If their location is of interest, it may be followed by GPS, for example. Because of the changing location of users location-sensitive services form a natural option in the case of mobile systems. 
At the level of IS specifications one specifies the functionality of the system in detail. If it was decided at the level of the application concept that the application will be context-aware proving context-aware IS services, one must specify in detail how the provided functionality is made context-aware.

Mobile devices include user interface problems of their own that have been discussed, for example, by Pascoe et al. (2000) and York and Pendharkar (2004). In addition to the micro-mobility of the mobile devices one can imagine display mobility, i.e. the depending on the alternative display devices available in the user's current location, the system selects the most appropriate display device available (e.g. PDA, TV set) possibly depending on the user's current attention (Banavar and Bernstein, 2002).

The datalogical/technical level includes implementation issues such as software on mobile terminals, capabilities of mobile devices, middleware for mobile applications and wired and wireless networks (Varshney and Vetter, 2002). The capacity of the handheld devices is limited and the network connectivity may vary. From the viewpoint of the user the mobile device together with the connected network forms a distributed information/database system. The data required for the service may reside in different nodes of the network. Even though necessary and useful, the wireless access to World Wide Web is a limited solution, since it assumes that the processing takes place in predetermined nodes. In the mobile environment there is a natural need to have mobile data and mobile programs, which are able to migrate in the network depending on the access and availability of capacity (Pitoura et al., 2001). It is beyond the scope of the present paper to discuss these implementation details.

\section{TOWARDS MOBILE INFORMATION SYSTEMS}

The proposed framework can be applied in classifying mobile applications and potentially in innovating new ones. One can start with mobile user, noting that even traveling, visiting and/or wandering users (Kristoffersen and Ljungberg, 1999) do not form homogenous categories. Traveling in a train obviously differs from traveling in a car, if one also drives the car. Also from the point of use, traveling in a train with a seat is quite different from traveling without a seat. Also visiting differs depending on whether one has a convenient wired access to computers or not.

Fieldwork is an example of mobile users doing mobile activity. It has received considerable attention in the context of mobile computing. As York and Pendharkar (2004) point out field workers form a very diversified group. 
Mobile entities form one natural application area for mobile information systems, if their location is of interest. The entities may be human beings, animals, vehicles or parcels.

One can identify more specific applications combining different aspects of mobility such as mobile users with mobile entities. Proxy Lady (Dahlberg et al., 2002) is an example of a mobile application supporting opportunistic communication of mobile users mainly in the work context. One can imagine an analogous mobile dating service in the context of big festivals, for example. Based on the user profile and preferences concerning the partner, the system might signal, if a suitable partner is in the vicinity.

The final case is mobile users doing mobile activity/work involving mobile entities of interest. One could speculate that this is the optimal context for mobile technology. However, this market niche may be quite restricted, since there is evidence that walking and working do not necessarily fit well together (Barnard et al, 2005). Walking tends to reduce the performance of work, since walking requires more attention than sitting or standing. Therefore it may be that mobile interaction is reasonable only when the nature of work is so inherently mobile that the user cannot interrupt its execution and make place and take time for the stationary interaction.

\section{FINAL COMMENTS}

This paper has attempted to analyse systematically the nature of and opportunities for mobile services and information systems. It has deliberately omitted various reasons to adopt mobile applications such as their impact on efficiency and effectiveness, customer and employee satisfaction, cost, and security (Nah et al., 2005). These are, of course pragmatically significant issues to be considered. Limited security and privacy of mobile computing and the danger of unwanted surveillance (Veijalainen and Visa, 2003) naturally lower customer trust in mobile applications (Siau and Shen, 2003) and slow down their adoption. The paper has also omitted the issue of how the development and delivery of mobile services can be organized in terms of content providers, application developers, service provides and network operators (Alahuhta, 2005; Varshney and Vetter 2002), with the idea that it is most important to consider first the system providing the services as a totality from the viewpoint of customers and users. It is the belief of the paper that the systematic understanding of the object of work, the mobile information system as the target of development, provides a useful starting point to consider of how to develop mobile applications and services.

The implications of the proposed metamodel for development can be summarized in the following seven points: 
- Analyse the mobility of work and/or activities to be supported by the system.

- Analyse the nature of mobility of the intended users of the system.

- Consider whether mobile interaction with the system is required or whether wireless stationary interaction is sufficient.

- Consider whether context-awareness of the application is required or adds sufficiently value to users.

- Consider what are the entities of interest to the users. Are any of them mobile and is the location information about them required?

- Specify the functionality of the system. If the application is to be contextaware, specify the context-awareness of the system in detail.

- Design the user interfaces of the system. If the system includes mobile entities, consider how their location and movement information is captured (automatically or as human inputting). In the case of output (service) users, consider how to represent the functionality of the system to the user, design the user interfaces and the user interaction, taking into account the nature of work, the interaction mode (stationary vs. mobile), possible context-awareness (possibly requiring special sensors), the attention required by the work outside the mobile device, and the restrictions and capacity imposed by the mobile devices available for the implementation.

\section{References}

Alahuhta, P., Ahola. J. and Hakala, H., 2005, Mobilizing Business Applications, TEKES, Technology Review 167/2005, Helsinki

Banava, G. and Bernstein, A., 2002, Software infrestructure and design challenges for ubiquitclis computing applications, Communications of the $A C M, 45(12): 92.96$

Barnard, L., Yi, J.S., Jacko, J.A. and Sears, A., (2005) An empirical cumparison of use-inmotion evaluation scenarios for mobile compuing devices, International Journal of $\mathrm{Hu}$ man-Computer Studies, (in press)

Dahlberg, P., Ljungberg, F. and Sanneblad, J., 2002, Proxy Lady: Mobile support for opportunistic interaction, Scandinavian Journal of Information Systems 14(1): 3-17

Dahlbom, B. and Ljungberg. F., 1998, Mobile Informatics, Scandinavian Journal of Information Systems, 10(1\&2): 227-234

Gorlenko, L. and Merrick, R., 2003, No wires attached: Usability challenges in the connected mobile world, IBM Systems Journal, 42(4): 639-651

Gustafsson, M.R., Karlsson, T. and Bubenko, J. Jr., 1982, A declarative approach to conceptual information modeling, in Olle, T.W., Sol, H.G. and Verrijn-Stuart, A.A. (eds.): Information systems design methodologies: a comparative review, North-Holland, Amsterdam: 93-142

Iivari, J., 1989, Levels of abstraction as a conceptual framework for an information system, in Falkenberg, E.D. and Lindgreen, P. (eds.), Information Systems Concepts: An In-Depth Analysis, North-Holland, Amsterdam: 323-352

Iivari J., 1990, Hierarchical spiral model foi information system and software development, Part 1: theoretical background, Information and Software Technology, 32(6): 386-399 
Iivari J., 1991, Object-oriented information systems analysis: A framework for object identification, in Shriver B.D (ed.), Proceedings of the Twenty-Fourth Annual Hawaii International Conference on Systems Sciences, Vol. II, IEEE Computer Society Press: 205-218

Iivari, J., 1994, Object-oriented information systems analysis: A comparison of six object-oriented analysis methods, in Verrijn-Stuart, A.A. and Olle, T.W. (eds.), Methods and Associated Tools for the Information Systems Life Cycle, IFIP Transactions A-55, North-Holland: $85-110$

Kristoffersen, S. and Ljungberg, F., 1999, "Making place" to make IT work: Empirical explorations of $\mathrm{HCI}$ for mobile CSCW, Proceedings of the International ACM SIGGROUP Conference on Supporting Group Work, ACM Press: 276-285

Krogstie, J., Lyytinen, K., Opdahl, A., Pernici, B. Siau, K. and Smolander K., 2003, Mobile information systems - Research challenges on the conceptual and logical levels, in Olivé A. (ed.), ER 2003 Workshop, LNCS 2784, Springer-Verlag, Berlin

Lilischkis, S., 2003, More Yo-yos, Pendulums and Nomads:Trends of Mobile and Multi-location Work in the Information Society, Issue Report 36, Star-project/Empirica.

Lyytinen, K. and Yoo, Y., 2002, Research commentary: The next wave of nomadic computing, Information Systems Research, 13(4): 377-388

Nah, F.F-H., Siau, K. and Sheng, P., 2005, The value of mobile applications: A utility company study, Communications of the $A C M, 48(2): 85-90$

Pascoe, J, Ryan, N. and Morse, D., 2000. Using while moving: HCI issues in fieldwork environments, ACM Transactions on Computer-Human Interaction, 7(3): 417-437

Perry, M., O'Hara, K., Sellen, A., Brown, B. and Harper, R., 2001, Dealing with mobility: Understanding access anytime, anywhere, ACM Transactions on Computer-Human Interaction, 8(4): 323-347

Pierre, S., 2001, Mobile computing and ubiquitous networking: concepts, technologies and challenges, Telematics and Informatics, 18: 109-131

Pitoura, E. and Samaras, G., 2001, Locating objects in mobile computing, IEEE Transactions on Knowledge and Data Engineering, 13(4): 571-591

Schmidt, A. Beigl, M. and Gellersen, H.-W., 1999, There is more to context than location, Computer \& Graphics, 23: 893-901

Siau, K. and Shen, Z., 2003, Building customer trust in mobile commerce, Comminications of the $A C M, 46(4): 91-94$

Siponen M.T., 2001, A Survey of the recent IS security development approaches: descriptive and prescriptive implications, in: Dhillon, G. (ed.), Information Security Management Global Challenges in the Next Millennium, Idea Group Publications Hershey, PA: 101-124

Tarasewich, P., 2003, Designing mobile commerce applications, Communications of the $A C M, 46(12): 57-60$

Tsalgatidou, A. and Pitoura, E., 2001, Business models and transactions in mobile electronic commerce: requirements and properties, Computer Networks, 37: 221-236

Varshney, U., 2003, Location management for mobile commerce applications in wireless Internet environment, ACM Transactions on Internet Technology, 3(3): 236-255

Varshney, U. and Vetter, R., 2002, Mobile commerce: Framework, applications and networking support, Mobile Networks and Applications, 7: 185-198

Veijalainen, J. and Visa, A., 2003, Guest editorial: Security in mobile computing environments, Mobile Networks and Applications, 8: 111-112

Urbaczewski, A., Valacich, J.S. and Jessup, L.M., 2003, Mobile commerce, Opportunities and challenges, Communications of the ACM, 46(12): 31-32

York, J. and Pendharkar, P.C., 2004, Human-computer interaction issues for mobile computing in a variable work context, International Journal of Human-Computer Studies, 60: [771-797 